\title{
Early Postnatal Lesion of the Medial Dorsal Nucleus Leads to Loss of Dendrites and Spines in Adult Prefrontal Cortex
}

\author{
Naydu Marmolejo ${ }^{a, c}$ Jesse Paez ${ }^{a} \quad$ Jonathan B. Levitt ${ }^{b, c}$ Liesl B. Jones ${ }^{a, c}$

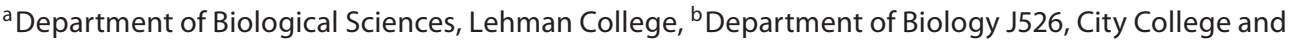 \\ 'Graduate Center, City University of New York, New York, N.Y., USA
}

\section{Key Words}

Schizophrenia · Calcium • Animal model $\cdot$ Dendrite $\cdot$

Prefrontal cortex

\begin{abstract}
Research suggests that the medial dorsal nucleus (MD) of the thalamus influences pyramidal cell development in the prefrontal cortex (PFC) in an activity-dependent manner. The $M D$ is reciprocally connected to the PFC. Many psychiatric disorders, such as schizophrenia, affect the PFC, and one of the most consistent findings in schizophrenia is a decrease in volume and neuronal number in the MD. Therefore, understanding the role the MD plays in the development of the PFC is important and may help in understanding the progression of psychiatric disorders that have their root in development. Focusing on the interplay between the MD and the PFC, this study examined the hypothesis that the MD plays a role in the dendritic development of pyramidal cells in the PFC. Unilateral electrolytic lesions of the MD in LongEvans rat pups were made on postnatal day 4 (P4), and the animals developed to $\mathrm{P} 60$. We then examined dendritic morphology by examining MAP2 immunostaining and by using Golgi techniques to determine basilar dendrite number and spine density. Additionally, we examined pyramidal cell density in cingulate area 1 (Cg1), prelimbic region, and dorsolateral anterior cortex, which receive afferents from the MD.
\end{abstract}

Thalamic lesions caused a mean MD volume decrease of $12.4 \%$ which led to a significant decrease in MAP2 staining in both superficial and deep layers in all 3 cortical areas. The lesions also caused a significant decrease in spine density and in the number of primary and secondary basilar dendrites on superficial and deep layer pyramidal neurons in all 3 regions. No significant difference was observed in pyramidal cell density in any of the regions or layers, but a nonsignificant increase in cell density was observed in 2 regions. Our data are thus consistent with the hypothesis that the MD plays a role in the development of the PFC and, therefore, may be a good model to begin to examine neurodevelopmental disorders such as autism and schizophrenia.

Copyright $\odot 2013$ S. Karger AG, Basel

\section{Introduction}

Normal development of the cerebral cortex is dependent upon reciprocal connections with the thalamus, and the close association between the medial dorsal nucleus (MD) and the prefrontal cortex (PFC) initiates early in development. The cortical plate differentiates from a densely packed zone of immature cells into laminae resembling future cortical layers [1]; axons from early postmitotic neurons of the cortical subplate pioneer the pathway from the cortex toward subcortical targets, prior to

\section{KARGER}

Fax +4161306 1234

E-Mail karger@karger.ch

www.karger.com (c) 2013 S. Karger AG, Basel

0378-5866/12/0346-0463\$38.00/0

Accessible online at:

www.karger.com/dne
Liesl B. Jones, $\mathrm{PhD}$

Department of Biological Sciences, Lehman College/CUNY

250 Bedford Park Blvd.

Bronx, NY 10468 (USA)

E-Mail liesl.jones@lehman.cuny.edu 
neurons from cortical layers $\mathrm{V}$ and VI migrating into position [2]. By postnatal days 4 and 5 (P4 and P5), layer V can be distinguished from the upper cortical plate containing the elements to become layers II and III. The first evidence of retrograde labeling from the PFC to the MD becomes apparent at this time [1]. The arrival of the MD afferent fibers in the upper cortical plate precedes the completion of layer III differentiation, occurring on days P9-10 [1]. The predominant thalamic input to the PFC is from the $\mathrm{MD}$, also known as medial thalamus, though medial prefrontal area 32 also makes extensive connections with the medial pulvinar $[3,4]$. Afferents from the MD synapse on spines and dendritic shafts of pyramidal cells in the PFC [5], and myelination of the axons from the MD to the PFC occurs approximately in the second decade of life [6]. Developmental maturation of PFC neurons is activity dependent $[7,8]$ and calcium dependent; an early lesion of the MD could, therefore, result in abnormal development of the PFC. In particular, a decrease in thalamic input to the PFC may result in a decrease of calcium-mediated stimulation of dendritic remodeling. The afferent input from the MD to the PFC is primarily excitatory. Binding of glutamate to the NMDA receptor causes an influx of calcium, which triggers the release of calmodulin from the calcium-binding protein neurogranin [9], allowing calmodulin to bind to calcium. The calcium-calmodulin complex can activate calmodulindependent protein kinase (CaMK) II [9], CaMK, and CaMK I and IV [10]. CaMK II has been shown to be important in controlling spine formation [11], as well as neuronal arborization both pre- and postsynaptically [12-14]. CaMK II phosphorylates MAP2, which in turn promotes dendritic branching. Dephosphorylation of MAP2 by calcineurin promotes dendritic elongation [1517]. Thus, changes in proteins involved in calcium signaling due to a loss of excitatory input may lead to changes in dendritic arbors and spines, which are critical to neuronal function, leading to possible alterations in the integration of synaptic inputs, and thus information transfer between cells can be altered [14]. Much evidence suggests that neurodevelopmental disorders occur as a result of an imbalance between excitation and inhibition [18]. Therefore, a decrease in cell number and volume in the MD may result in a loss of innervation to the PFC, which would result in loss of dendrites and spines and a loss of synaptic surface area which could result in an imbalance in excitation and inhibition. These deficits could be responsible for dysfunction of the PFC found in several different disorders such as schizophrenia, autism and attention deficit disorder.
Research has shown that lesions of the MD have produced a variety of deficits of working memory in rats [19, 20]. Deficits of spatial working memory [21] and visual recognition [22] are seen in monkeys similar to that observed in schizophrenia. Several studies showed alterations in working and short-term memory in adult rats following early NMDA receptor inhibition in the MD [23-28, for review see 29]. The above studies suggest that an early lesion of the MD or PFC can alter behavior in an adult. To determine if an early developmental insult to the MD leads to altered dendritic development of cortical pyramidal cells, we examined 3 rat PFC regions at day P60 that receive projections from the MD according to Gabbott et al. [30]: (1) prelimbic region (homologous to human area 32), (2) dorsolateral anterior cortex (homologous to Brodmann area 24b) [30] and (3) cingulate area 1 (Cg1) following a unilateral lesion at P4. It may be argued that a unilateral lesion may yield confounding results from the risk of commissural communication and from the absence of MD medial separation by ventricles [31, 32]. However, MD innervation of the PFC is unilateral $[33,34]$, and dendrites of MD neurons are confined to the nucleus and to within the segment of the MD where they arise [35-37]. Some thalamic afferents synapse onto callosal cells [35-37], and only $3 \%$ of corticothalamic afferents project contralaterally to anterior cingulate areas [34]; therefore, cross-fiber contamination may be negligible. Our data suggest that the development of the PFC may indeed be related to levels of excitatory input from the MD.

\section{Experimental Procedure}

\section{Lesion Protocol}

Timed-pregnant Long-Evans rats were obtained from Jackson Laboratories, and the day of birth was designated as P0. The surgery was performed on $\mathrm{P} 4$. $\mathrm{P} 4$ was chosen because in rats mediodorsal afferents first arrive at the PFC between P1-7, and the reciprocal afferents from the PFC back to the thalamus develop during P4-9 [1]. We believe that altering communication between the thalamus and the PFC during the period of brain development when they can impact each other may give a better understanding of whether normal development of the PFC depends on intact thalamic inputs. Because only $3 \%$ of corticothalamic afferents project contralaterally, we believe there is minimal risk of cross-fiber contamination, so we did not have a sham-operated control group and each animal was therefore its own control. Rat pups were anesthetized with an intraperitoneal injection of ketamine $(75 \mathrm{mg} / \mathrm{kg})$ plus xylazine $(6-8 \mathrm{mg} / \mathrm{kg})$. The scalp was reflected to expose the skull, and a small opening was made over the appropriate brain region. Because the skull had not ossified, scissors were used to cut an opening for the electrode to penetrate the brain. Preliminary 


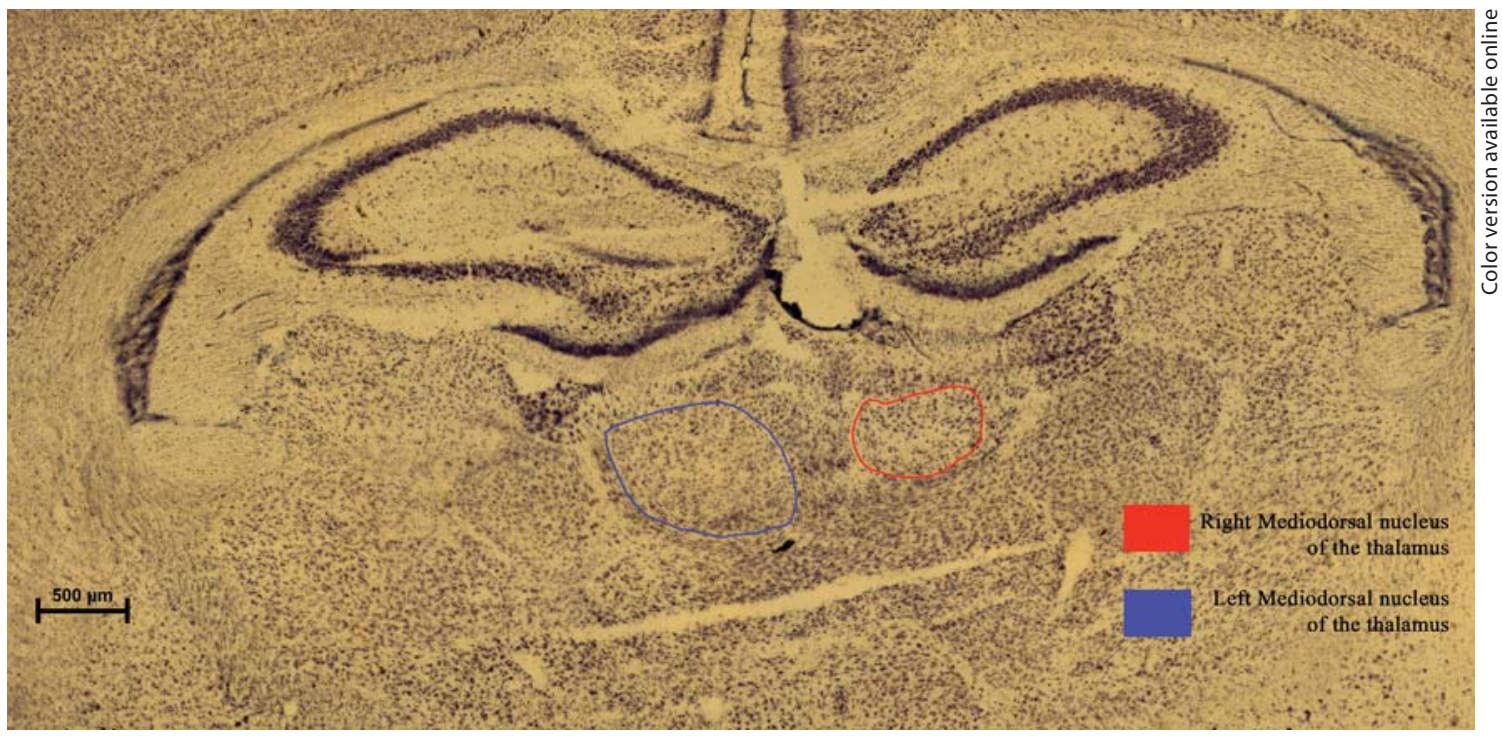

Fig. 1. Photomicrographs of rat MD in P14 control (left) vs. lesioned (right) hemispheres. The MD in the rat is bounded by the intermedullary lamina. Scale bar $=500 \mu \mathrm{m}$.

experiments showed the MD at $\mathrm{P} 4$ to be located $4.8 \mathrm{~mm}$ rostral to lambda and $0.75 \mathrm{~mm}$ lateral to the midline. A tungsten-in-glass microelectrode was inserted $6 \mathrm{~mm}$ deep into the right hemisphere at this location, where a current of $5 \mu \mathrm{A}$ (tip negative) was passed for $3 \mathrm{~s}$. The coordinates were determined by measurements from nonlesioned rats stained with thionin and compared to the atlases of Paxinos et al. [31] and Paxinos and Watson [32]. To determine if the lesion was confined to the MD, we examined the thalamus at P14 following a lesion at P4 (fig. 1). We determined that the coordinates were accurate, and the lesion was confined to the MD. The pups received an electrolytic lesion in the thalamus of one hemisphere; the right MD was lesioned while the left was left intact. The incisions were closed, and the pups were returned to the mother and allowed to survive to P60. At this time, the pups received an overdose of sodium pentobarbital and were perfused transcardially with $0.9 \%$ saline followed by phosphate-buffered $4 \%$ paraformaldehyde. The brains were postfixed in situ overnight. Following postfixation the brains were then removed from the skull and exposed to increasing gradients of sucrose solution in phosphate-buffered saline (PBS) for cryoprotection, after which serial coronal $50-\mu \mathrm{m}$-thick frozen sections through the cortex were cut on a sliding microtome. Every section was collected to be processed for either immunohistochemistry or histological staining. The sections were stored in a cryoprotectant at $-70^{\circ} \mathrm{C}$ until they were processed for either thionin or immunohistochemistry. The lesions and analysis were performed by the same person. Analysis of sections was not done blindly, but the same material was analyzed independently by several members of the laboratory with similar results, suggesting no bias.

Areas of Interest

Prefrontal Cortex

In the adult rat the PFC extends from the frontal poles to the rostral end of the corpus callosum. The prelimbic area (homolo- gous to human area 32) is on the midline just dorsal to the peduncular cortex and rhinal fissure and ventral to area Cg1 [31]. The dorsolateral anterior cortex is dorsal and lateral to area Cg1 [31]. We referred to Paxinos et al. [31] and Paxinos and Watson [32] to locate the gross borders of the prelimbic area. To distinguish the cytoarchitectural borders of the prelimbic and dorsolateral anterior cortex, we used criteria from Gabbott et al. [30] and Paxinos et al. [31]. All sections were counterstained with thionin to determine cytoarchitectural boundaries. Cg1 is completely dysgranular whereas the prelimbic region has a very thin layer IV. All of the sections that contained the prefrontal regions were used for immunohistochemistry.

\section{MD of the Thalamus}

The MD is easily distinguished in thionin-stained sections. Eighty percent of its boundary is formed by the intermedullary lamina, which encircles the MD. The remaining boundary is formed by the paraventricular nucleus (fig. 2). Using these boundaries we determined the location of the MD on the sham-lesioned side as well as the lesioned side.

\section{Histological Procedures}

Sections were stained using thionin to better differentiate areal and laminar boundaries, to determine MD volumes and to perform cell counts both in the MD and the PFC. The slides were mounted and defatted by increasing gradients of ethyl alcohol, exposed to xylene for $10 \mathrm{~min}$, and then rehydrated and stained with thionin. Sections were then dehydrated, cleared and coverslipped.

\section{MAP2 Immunohistochemistry}

An antibody from Chemicon (Temecula, Calif., USA) was used specifically for MAP $2_{\mathrm{a}}$ and $\mathrm{MAP} 2_{\mathrm{b}}$, which correspond to the two high molecular weight forms found in the adult brain. Sections 


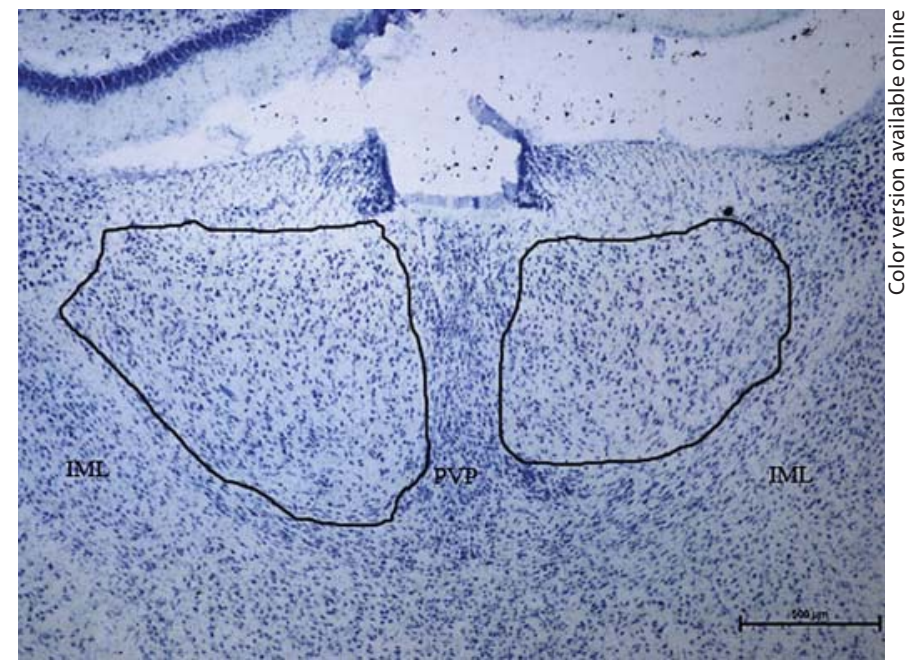

Fig. 2. Photomicrographs of rat MD in P60 control (left) vs. lesioned (right) hemispheres. The MD in the rat is bounded by the intermedullary lamina (IML). Scale bar $=500 \mu \mathrm{m}$. PVP $=$ Posterior paraventricular nucleus.

were removed from the cryoprotectant and washed in PBS 3 times, then pretreated with $3 \%$ hydrogen peroxide for $10 \mathrm{~min}$ to remove any endogenous peroxidase. Sections were again washed 3 times with PBS, followed by $1 \mathrm{~h}$ incubation in a blocking solution of $4 \%$ instant milk in PBS (BLOTTO) with $0.2 \%$ Triton X. Following the blocking procedure, sections were incubated in a primary antibody in a 1:500 dilution overnight on an orbital shaker. The next day the sections were washed with PBS and treated with a biotinylated anti-mouse secondary antibody (Vector Laboratories, Burlingame, Calif., USA) solution diluted 1:100 for $1 \mathrm{~h}$. After 3 PBS washes, the sections were treated with a tertiary solution (ABC kit; Vector Laboratories) to allow for greater sensitivity and decreased background staining, followed by a standard diaminobenzidine reaction to visualize the label. The sections were then mounted on slides, dehydrated, defatted and coverslipped. Following area fraction analysis, the coverslips were removed and the sections were counterstained with thionin for neuron density measurements.

\section{Golgi Method}

The frontal cortex anterior to the bregma was severed from the more caudal portion of the brain. Frontal cortices were wrapped in clean gauze and immersed in $100 \mathrm{ml}$ of Golgi solution. Both the Golgi solution and gauze were changed after $24 \mathrm{~h}$, followed by extended 12-week incubation in the dark. After impregnation, the tissue was dehydrated through increasing gradients of alcohol followed by 3 -day incubations in serial celloidin. The tissue was put in paper boats and allowed to harden in chloroform. Twelve percent Parlodion was added to the paper boats, and the boats and tissue were stored for 3-24 h until hardened, after which 200- $\mu \mathrm{m}$ thick serial sections were cut on a vibratome and collected in $70 \%$ alcohol. The sections were washed in distilled water, incubated in $19 \% \mathrm{NH}_{4} \mathrm{OH}$ for $30 \mathrm{~min}$, and rinsed again in water. They were then fixed in Kodak Rapid Fix, followed by a final wash in distilled water. The sections were dehydrated in graded ethanol starting at $50 \%$, defatted in toluene, mounted onto slides and coverslipped.

\section{Quantification of the MD Volume}

The material was quantified using a Bioquant image analysis system interfaced with an Olympus AX70 microscope and a Sony 3 -chip color camera. The area of the MD was determined for each slide by drawing a contour around the nucleus. The specimen thickness was calculated as an average of three randomly selected slides. Slides were chosen by determining the total number of slides available for analysis and dividing them into three equal groups. The first slide was chosen using a randomized start determined by the image analysis program. The second slide was determined by equal spacing from the first slide, and the third slide was determined by equal spacing from the second. MD volume was then obtained by multiplying the summed nuclear area by section thickness and the number of sections through each nucleus. Volumes of lesioned nuclei were compared to controls to calculate percent variation. Because we lesioned only one hemisphere (the right) we used the left as a control; thus each animal acted as its own control. Only brains that met the criterion of an MD lesion $\geq 9 \%$ were included in the MAP2 analysis.

\section{Quantification of Cell Density in the MD and PFC}

Cells were counted in four randomly selected thionin sections. Slides were chosen in the same manner as that for the MD volume measurements. Contours were traced around the selected region, and a counting grid was superimposed on the contour. Every third intersection was marked, with a random start, so that $30 \%$ of the intersections were marked. A counting box of $100 \times 100$ $\mu \mathrm{m}$ was centered at the marked intersections. Counting was done using a $40 \times$ objective under oil. Cells were counted if they had a distinguishable nucleolus, except for those touching the exclusion lines. Neuron density was determined by dividing the average number of cells per box by the volume of the counting box. The volume of the disector was calculated as the product of the area of the counting frame and the average thickness of the section corrected for shrinkage. The estimate of the total number of neurons in the MD was determined as the average neuron density of four randomly selected sections multiplied by the total nucleus volume. The neuron density in the PFC reflects the density of the pyramidal cells in layers II-III and V.

\section{Area Fraction of MAP2}

We measured area fraction in both superficial and deep layers in the regions of interest in the PFC. Every section was included in the analysis, thus removing bias from selecting the sections that stained best with MAP2 and allowing for a more accurate assessment of the brain region. The thalamic measurements were not done blindly, but the MAP2 area fraction measurements were shared between two investigators, one of whom was blinded.

Within a defined sampling box, area fraction refers to the ratio of the area occupied by MAP2 immunostaining to the total area of the box. The sampling box is a square with each side equal to the width of the lamina. Bioquant software was employed to select pixels within the sampling box that matched threshold criteria for MAP2-positive immunostaining. The threshold was set at the level that selected the lightest stained cell bodies and dendrites without selecting background staining. The setting for illumination was kept constant throughout the analysis. The computer outlined and added the threshold areas and determined the ratio of the stained area to the total area of the sampling box. Eight sampling boxes were examined per section (4 within deep layers and 
4 within superficial layers). The 4 sampling boxes were taken consecutively as long as there were no histological artifacts in the tissue and the lamina could be determined. If there were artifacts in the tissue, then the box was placed at the next straight edge after the artifact to avoid distortion due to round pial edges. Area fraction was averaged for all sampling boxes within a particular lamina for each brain.

\section{Basilar Dendrite Counts}

A Bioquant image analysis system interfaced with an Olympus AX70 microscope connected to a Ludl motorized stage and a SONY 3-chip camera was used to count the number of primary and secondary dendrites. A contour was drawn to outline each lamina separately in each of the regions of interest in the PFC. A counting grid was placed inside the contour, and the computer randomly selected half of the intersections to be measured with a counting box of $100 \times 100 \mu \mathrm{m}$ placed inside the marked grids. The dendrites of the cells within the grid that met the criteria were counted using a $40 \times$ Plan Apo objective under oil. Basilar dendrites of the selected neurons were counted, even if they extended beyond the boundaries of the counting box. Twenty cells per layer per region were assessed for each brain.

\section{Spine Density}

A Bioquant image analysis system interfaced with an Olympus AX70 microscope connected to a Ludl motorized stage and a SONY 3-chip camera was used to count the number of primary and secondary dendritic spines. A contour was drawn to outline each lamina separately in each of the regions of interest in the PFC. A counting grid was placed inside the contour, and the computer randomly selected half of the intersections to be measured with a counting box of $50 \times 50 \mu \mathrm{m}$ placed inside the marked grids. The spines on the primary and secondary branches off the somata within the grid, which met the criteria, were counted using a $100 \times$ Plan Apo objective under oil. Dendritic spines of the selected neurons were counted even if the basilar dendrites extended beyond the boundaries of the counting box. Ten cells per layer per region were assessed for each brain.

\section{Sholl Analysis of Spine Density}

Five neurons per layer per cortical region were traced for each brain. The soma was traced first, followed by every single basilar dendrite with its primary and secondary segments. Every spine emanating from the primary and secondary segments was traced. While the dendritic processes were traced on a 2-dimensional model, the software registered the 3-dimensional coordinates for every point allowing an exact virtual reconstruction of the dendritic tree. To assess the complexity of the dendritic tree, Sholl analysis was performed using Neurolucida and Neuroexplorer software. For this task, concentric shells at equidistant spaces were generated around the center of the soma, and the number of intersections of the dendritic segments within each shell was counted.

\section{Statistical Analysis}

The principal comparisons made are between lesioned and unlesioned brain hemispheres. Because specimens were immunostained in matched pairs, the data were analyzed by paired $t$ tests. Two-tailed probabilities were employed to test the hypothesis that a lesion of the MD would cause a change in MAP2 im- munostaining in the PFC following a lesion of the MD at P4. Our data showed a decrease in MAP2 area fraction analysis, and therefore subsequent analysis employed one-tailed probabilities testing the directional hypothesis that an early postnatal lesion of the MD would cause a decrease in basilar dendrites and spines. Data are reported as means \pm standard deviation. To determine the reliability of area fraction analysis, an intraclass correlation was performed on the means from the raw data of the control population from the schizophrenic study [38]. An intraclass correlation examines the reliability of a method. Data from every control brain $(\mathrm{n}=7)$ were included in the calculation. Our intraclass correlation was 0.90 , which suggests a high correlation and reliability of the methods, suggesting that area fraction is a reliable measure of immunostaining.

\section{Results}

\section{Volumes and Cell Counts}

MD nuclei of 5 animals were lesioned for the MAP2 study. The lesions ranged in size from 4.1 to $23.4 \%$ compared to the opposite hemisphere (fig. 2, 3). Our criterion for including brains in this study was based on lesion size. In human studies, schizophrenic MD volume decreases ranged from 8 to $25 \%$. To more closely mimic human schizophrenia studies, we chose to include brains whose lesions fell within that range [3, 39-44]. Brains with MD lesions smaller than $9 \%$ were not used in the study; therefore, R20, whose lesion was less than 9\%, was excluded from further study. Each animal was used as its own control; therefore, paired t tests were used to determine significance comparing left and right thalami. Brains with lesions $\geq 9 \%$ had a significant average decrease of $12.4 \%$ (control $=0.0366 \mathrm{~mm}^{3}$, lesion $=0.0321 \mathrm{~mm}^{3}, \mathrm{p}=0.00009$, $\mathrm{t}=21.7)$. The same 4 brains were used to determine cell loss in the MD due to the lesion. The MD is a defined nucleus allowing for accurate cell counts. There was a significant $11 \%$ decrease in total cell number in the MD (control $=45,889.35$, lesion $=40,912.6, p=0.04, t=2.6$ ) for the brains examined in the MAP2 study (fig. 3). For the Golgi study we analyzed the brains of 9 animals that had received an electrolytic lesion to the MD in the right hemisphere. The lesions ranged in size from 0.89 to $17.64 \%$. Brains with lesions smaller than 9\% were not used in the study; therefore, R28, R31 and R35, with corresponding lesions of $8.13,5.26$ and $0.89 \%$, were excluded from further study. The mean MD volume was decreased by $14.82 \%$ as a result of the lesion (fig. 3). The 6 brains were examined for cell loss in the MD due to the lesion. Figure 3 shows that there was an average decrease in total cell number of 23.43\% (control: 4,947.5 $\pm 1,539.7$ vs. lesion: 3,719.4 \pm 976.4, $\mathrm{p}=0.0044, \mathrm{t}=4.92$ ) for the brains examined. 


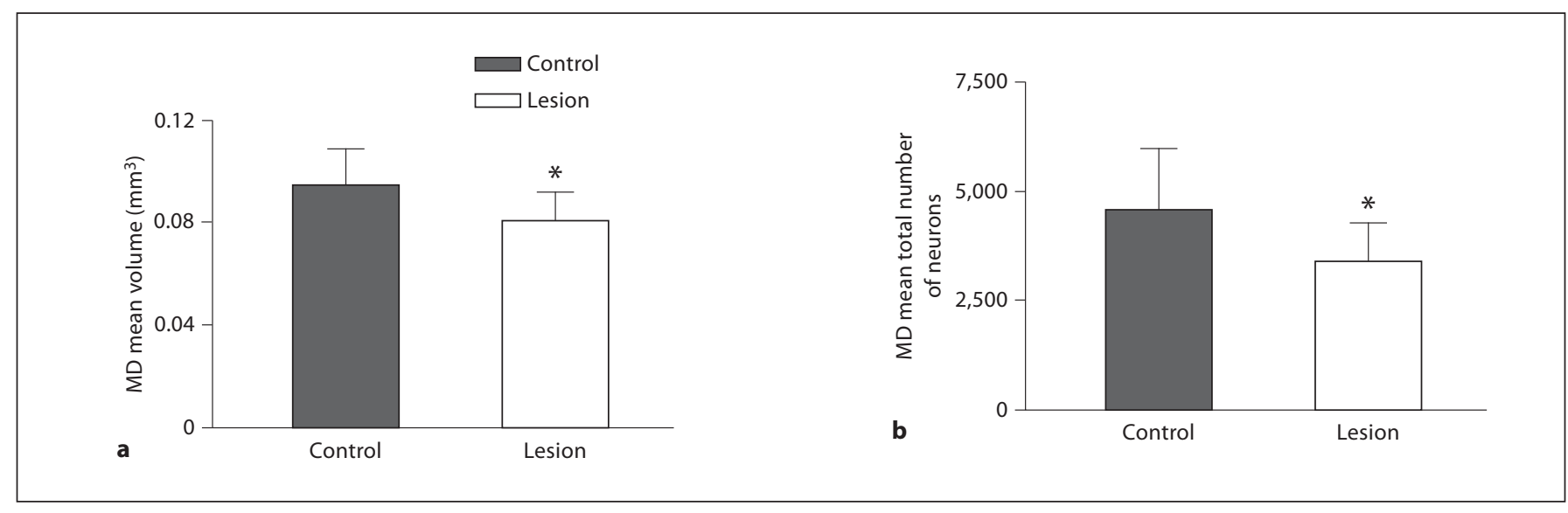

Fig. 3. Histograms showing average decrease in MD volumes (a) and cell number (b): control vs. lesioned hemispheres. All of the animals showed a decrease in volume and cell number in the MD at P60 following a lesion of the MD at P4. ${ }^{*}$ Significant difference.

Fig. 4. Example of MAP2 immunostaining in P60 prelimbic cortex in unlesioned (a) and lesioned (b) hemispheres following a unilateral MD lesion at P4. The pial surface is to the right in each panel.
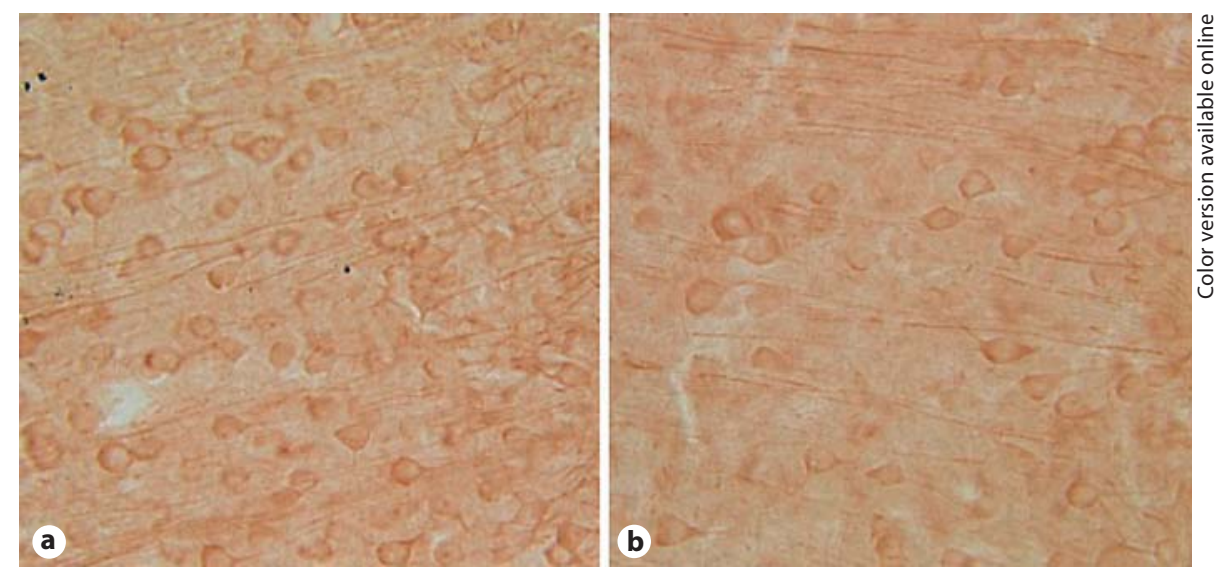

\section{MAP2 Area Fraction}

Three PFC regions were examined in P60 rats for changes in MAP2 expression following an MD lesion at P4 (fig. 4, 5). Paired t tests were used to determine significance. We examined superficial layers (deep layer II and layer III) and deep layers (layer V) using area fraction analysis. While area fraction analysis does not directly measure changes in expression of the protein, it does measure differences in staining patterns and the amount of stain in a given cell population, which suggests loss of protein or alterations in the rate of expression of the protein. Our results suggest loss of MAP2, a protein expressed in dendrites and spines, and our Golgi data confirm loss of dendrites and spines. In the prelimbic area there was a significant $26 \%$ decrease in MAP2 immunostaining in the superficial layers (control $=0.023$, lesion $=$
0.017, $\mathrm{p}=0.03, \mathrm{t}=3.27$ ). In the deep layers there was a significant $34.7 \%$ decrease in MAP2 immunostaining (control $=0.023$, lesion $=0.015, \mathrm{p}=0.0028, \mathrm{t}=6.59$ ). In the dorsolateral anterior area there was a significant $28 \%$ reduction in MAP2 immunostaining in the superficial layers (control $=0.025$, lesion $=0.018, \mathrm{p}=0.04, \mathrm{t}=2.96$ ). There was a similar $26 \%$ reduction in the deep layers (control $=0.023$, lesion $=0.017, \mathrm{p}=0.006, \mathrm{t}=6.22$ ). In Cg1 there was a significant $28.6 \%$ reduction in immunostaining in the superficial layers (control $=0.021$, lesion $=$ $0.015, \mathrm{p}=0.0034, \mathrm{t}=6.22$ ). There was a similar $27.3 \%$ significant reduction in immunostaining in the deep layers (control $=0.022$, lesion $=0.016, \mathrm{p}=0.008, \mathrm{t}=4.898$ ). Two brains, RL1 and RL3, did not have a lesion, and there was no difference in area fraction between the left and right side. 


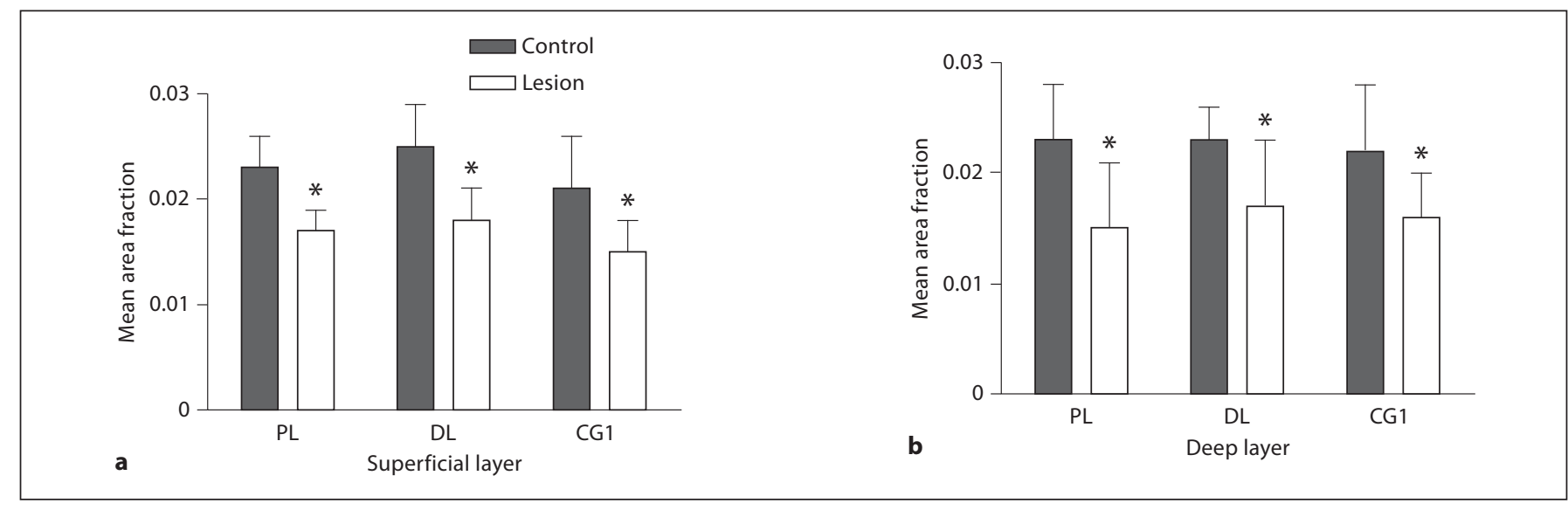

Fig. 5. Histograms showing the average decrease in area fraction analysis for the 3 PFC regions examined. In all regions in the superficial (a) and deep layers (b) there was a significant decrease in MAP2 staining on the lesioned hemisphere (open bars) compared to the control or unlesioned hemisphere (filled bars). PL = Prelimbic; $\mathrm{DL}=$ dorsolateral; $\mathrm{CG} 1$ = cingulate cortex $1 .{ }^{*}$ Significant decrease.

\section{PFC Cell Density}

To determine if the MD lesion caused retrograde cell loss, we examined pyramidal cell density in each of the 3 regions (fig. 6). The cortical regions are very large, making it difficult to perform accurate cell counts, so density measurements were performed instead. In the prelimbic region there was no significant change in the superficial layers (control $=1,406.06$, lesion $=1,461.82, \mathrm{p}=0.23, \mathrm{t}=$ -1.41 ) or in the deep layers (control $=1,511.4$, lesion $=$ $1,538.8, \mathrm{p}=0.53, \mathrm{t}=-0.69$; fig. 6 ). In the dorsolateral anterior region we found no significant change in pyramidal cell density in the superficial layers (control $=2,295.7$, lesion $=2,291.9, \mathrm{p}=0.98, \mathrm{t}=0.033$; fig. 6). In the deep layers we found a nonsignificant increase in cell density (control $=2,632.18$, lesion $=2,817.58, \mathrm{p}=0.58, \mathrm{t}=-0.60$ ). In the third region, Cg1, we found no difference in cell density in the superficial layers $($ control $=612.18$, lesion $=$ $609.46, p=0.76, t=0.33$ ). In the deep layers we found a nonsignificant increase in cell density (control $=664.08$, lesion $=718.44, \mathrm{p}=0.66, \mathrm{t}=-0.47$; fig. 6 ).

\section{Basilar Dendrites}

The same 3 PFC regions were examined in P60 rats for changes in basilar dendrites due to an MD lesion at P4 (fig. 7). The number of basilar dend rites on pyramidal cells decreased in lesioned hemispheres compared to the unlesioned hemispheres in the dorsolateral anterior region. In the superficial layers of the dorsolateral anterior cortex there were $24.24 \%$ fewer primary dendrites in lesioned hemispheres than in controls (control: $4.62 \pm$

MD Influences Dendritic Development of Pyramidal Cells in the PFC

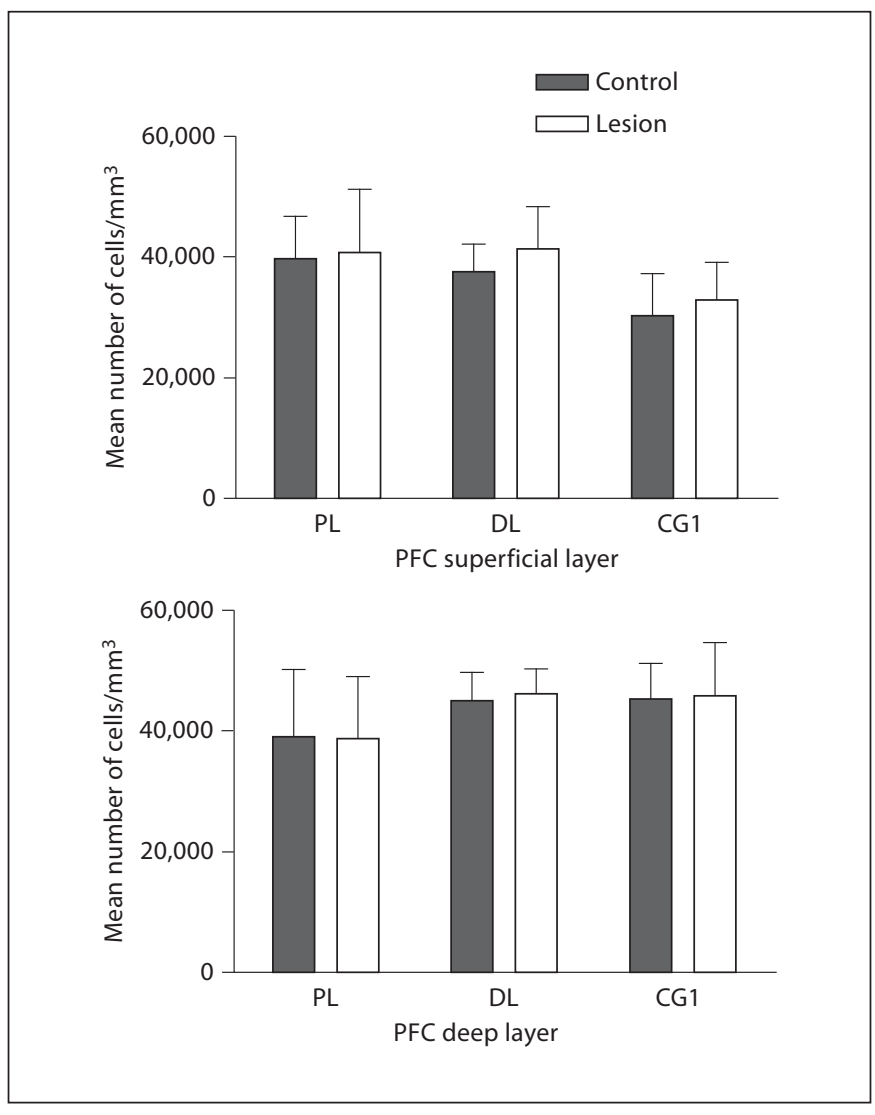

Fig. 6. Histograms showing the average pyramidal cell density in the deep layers in the 3 PFC regions examined. There was no difference in density in any of the regions in control (filled bars) vs. lesioned (open bars) hemispheres. PL $=$ Prelimbic; DL $=$ dorsolateral; CG1 = cingulate cortex 1 .

Dev Neurosci 2012;34:463-476 


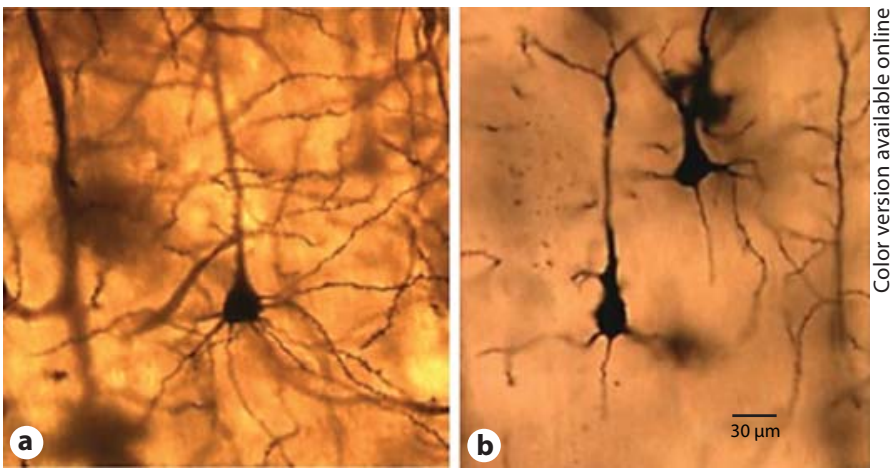

Fig. 7. Photomicrograph of Golgi staining at P60 control (a) vs. lesion (b) following a unilateral lesion of the MD at P4.

0.73, lesion: $3.5 \pm 0.36, \mathrm{p}=0.0059, \mathrm{t}=4.59$; fig. 8). The difference in the deep layer was not as pronounced, $14.55 \%$, but was still significant (control: $4.4 \pm 0.73$, lesion: $3.76 \pm 0.85, \mathrm{p}=0.016, \mathrm{t}=3.57$; fig. 8 ). The loss of secondary dendrites was more pronounced compared to the primary dendrites. There was a $40.46 \%$ decrease in the superficial aspect (control: $7.76 \pm 0.53$, lesion: 4.62 $\pm 0.36, \mathrm{p}=0.000043, \mathrm{t}=13.2$; fig. 8 ), and a $30.04 \%$ decrease of secondary basilar dendrites in the deep layer (control: $7.19 \pm 0.61$, lesion: $5.03 \pm 0.5, \mathrm{p}=0.00021, \mathrm{t}=$ 9.54; fig. 8).

In the prelimbic area there was a significant $25 \%$ (control: $4.72 \pm 0.81$, lesion: $3.54 \pm 0.37, \mathrm{p}=0.0031, \mathrm{t}=$ 5.35) and $24.84 \%$ (control: $4.71 \pm 0.72$, lesion: $3.54 \pm$ $0.33, \mathrm{p}=0.002, \mathrm{t}=5.790$ ) decrease in primary dendrites in the superficial (fig. 8) and deep layers, respectively (fig. 8). As seen in the dorsolateral anterior region, the secondary dendrites showed a more prominent difference across both layers: $39.70 \%$ for superficial cells (control: $7.28 \pm 1.24$, lesion: $4.39 \pm 0.61, \mathrm{p}=0.0016, \mathrm{t}=6.19$; fig. 8 ) and $31.84 \%$ for cells found in the deep cortex (control: $7.13 \pm 0.81$, lesion: $4.86 \pm 0.76, \mathrm{p}=0.0015, \mathrm{t}=6.3$; fig. 8).

Cg1 showed similar reductions in basilar dendrites; the number of primary dendrites was decreased by $25.31 \%$ (control: $4.82 \pm 0.79$, lesion: $3.6 \pm 0.37, \mathrm{p}=0.008, \mathrm{t}=$ 4.89) in superficial layers and by $23.06 \%$ (control: $4.77 \pm$ 0.998 , lesion: $3.67 \pm 0.4, \mathrm{p}=0.022, \mathrm{t}=3.66$; fig. 8 ) in deep layers, while there were substantially fewer secondary dendrites in lesioned hemispheres: $39.74 \%$ in superficial (control: $7.7 \pm 0.48$, lesion: $4.64 \pm 0.40, \mathrm{p}=0.00016, \mathrm{t}=$ 13.74 ) and $34.41 \%$ in deep (control: $7.73 \pm 1.07$, lesion: $5.07 \pm 0.44, \mathrm{p}=0.0012, \mathrm{t}=8.16$; fig. 8), mirroring the effects found in the previous cortical region.

\section{PFC Dendritic Spines}

The spines on primary dendrites were significantly reduced for superficial and deep layers of Cg1: 53.4\% (control: $26.1 \pm 9.36$, lesion: $12.16 \pm 2.72, \mathrm{p}=0.03, \mathrm{t}=3.31)$ and $28.6 \%$ (control: $22.26 \pm 7.80$, lesion: $15.86 \pm 5.15$, $\mathrm{p}=0.048, \mathrm{t}=2.82$ ), respectively (fig. 9). Prelimbic superficial (control: $21.78 \pm 7.37$, lesion: $15.03 \pm 5.21, \mathrm{p}=0.06$, $\mathrm{t}=2.4263$ ) and deep (control: $21.35 \pm 8.38$, lesion: 12.5 $\pm 4.079, \mathrm{p}=0.21, \mathrm{t}=1.4481$ ), and dorsolateral anterior superficial (control: $15.4 \pm$ 5.912, lesion: $10.95 \pm 1.302$, $\mathrm{p}=0.12, \mathrm{t}=1.8837$ ) and deep (control: $12.92 \pm 2.9$, lesion: $11.4 \pm 2.112, \mathrm{p}=0.078, \mathrm{t}=2.2121)$ cortical regions displayed tendencies towards decreased primary dendritic spines but did not reach statistical significance (fig. 9).

Spines on the secondary dendrites were significantly reduced in the lesioned hemisphere versus the intact side for all 3 cortical regions and evident in both superficial and deep layers. In the prelimbic cortex, secondary dendritic spines showed a decrease across both layers: $32.4 \%$ for superficial cells (control: $90.52 \pm 11.041$, lesion: 61.17 $\pm 5.694, \mathrm{p}=0.0003, \mathrm{t}=9.1562$ ) and $46.2 \%$ for cells found in the deep cortex (control: $97.03 \pm 17.12$, lesion: $52.21 \pm$ 9.874, $\mathrm{p}=0.0006, \mathrm{t}=7.8088$ ). In the Cg1, there were substantially fewer secondary dendritic spines in lesioned hemispheres: $46.6 \%$ superficially (control: $100.32 \pm$ 27.94, lesion: $53.6 \pm 4.76, \mathrm{p}=0.013, \mathrm{t}=4.25)$ and $46.91 \%$ deep (control: $101.4 \pm 34.66$, lesion: $53.83 \pm 8.35, \mathrm{p}=$ $0.021, t=3.69)$. This pattern of decline was also seen in the dorsolateral anterior cortex, where there were considerably fewer secondary dendritic spines in the lesion hemispheres: $37.2 \%$ decrease in the superficial aspect (control: $118.8 \pm 5.705$, lesion: $74.08 \pm 4.68, \mathrm{p}=0.00006$, $\mathrm{t}=12.099$ ), and $41.6 \%$ decrease in the deep layer (control: $101.1 \pm 6.818$, lesion: $59.28 \pm 4.015, \mathrm{p}=0.00016, \mathrm{t}=$ 10.174; fig. 9).

\section{Sholl Analysis: Spine Density}

To better understand the alterations in spine density, we examined the density of spines versus the distance from the soma. Using Sholl analysis, somata, with radiating primary and secondary basilar dendrites, were traced for neurons in the superficial and deep layers of all 3 PFC regions. The pooled Sholl curve of the pyramidal neurons from the lesion hemisphere was located markedly below the Sholl curve of cells from the control side, at each distance from the soma (fig. 10). The statistical significance of the reduction in spine density was assessed for proximal segments (when the radius of the concentric shell intersecting the dendritic tree was $20 \mu \mathrm{m}$ ) and for distal segments (radius $=60 \mu \mathrm{m}$ ). Cells analyzed at $20 \mu \mathrm{m}$ in 


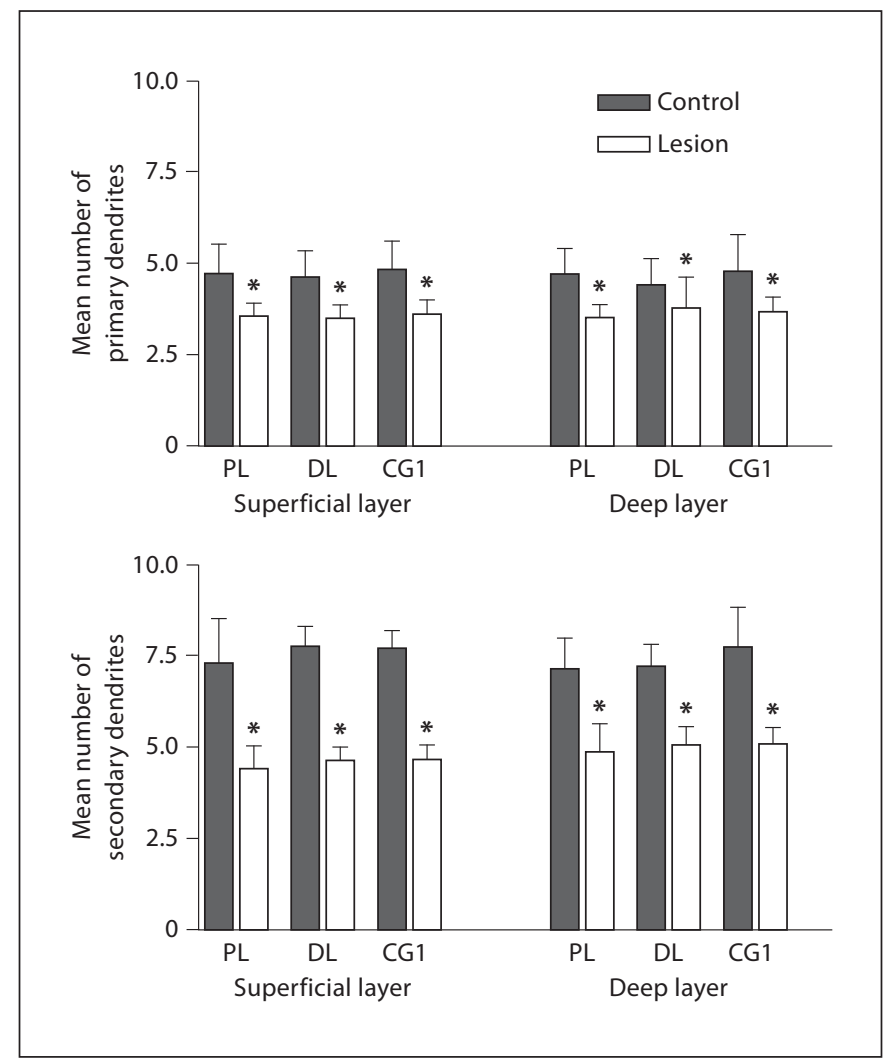

Fig. 8. Histograms showing the mean number of primary and secondary basilar dendrites at P60 in the superficial and deep layers following a lesion at $\mathrm{P} 4$. The data show a decrease in both primary and secondary basilar dendrites in all 3 regions in the lesion vs. the controls. $\mathrm{PL}=$ Prelimbic; $\mathrm{DL}=$ dorsolateral; $\mathrm{CG} 1=$ cingulate cortex $1 .{ }^{*}$ Significant decrease.

Cg1 in superficial layers showed no significant decrease in spine density (control: $0.125 \pm 0.057$, lesion: $0.098 \pm$ $0.079, \mathrm{p}=0.135, \mathrm{t}=2.41)$. At $60 \mu \mathrm{m}$ there was a significant $38.5 \%$ decrease in spine density (control: $0.41 \pm 0.153$, lesion: $0.324 \pm 0.178, \mathrm{p}=0.03, \mathrm{t}=3.27$ ). In deep layers both proximal and distal segments showed significant decreases in spine density. At $20 \mu \mathrm{m}$ there was a $40 \%$ decrease in spine density (control: $0.1004 \pm 0.078$, lesion: $0.04 \pm 0.038, \mathrm{p}=0.004, \mathrm{t}=4.92)$. At $60 \mu \mathrm{m}$ there was a significant $37 \%$ decrease in spine density (control: 0.441 \pm 0.13 , lesion: $0.276 \pm 0.1, \mathrm{p}=0.00004, \mathrm{t}=13.2$ ). Cells analyzed in the prelimbic region in superficial layers showed significant decreases in spine density at both 20 and $60 \mu \mathrm{m}$. At $20 \mu \mathrm{m}$ there was a significant $47 \%$ decrease in spines (control: $0.1207 \pm 0.069$, lesion: $0.064 \pm$ $0.055, \mathrm{p}=0.004, \mathrm{t}=4.92)$. At $60 \mu \mathrm{m}$ there was a significant $37.47 \%$ decrease in spine density (control: $0.483 \pm 0.14$, lesion: $0.302 \pm 0.18, \mathrm{p}=0.001, \mathrm{t}=7.17)$. In the deep layers
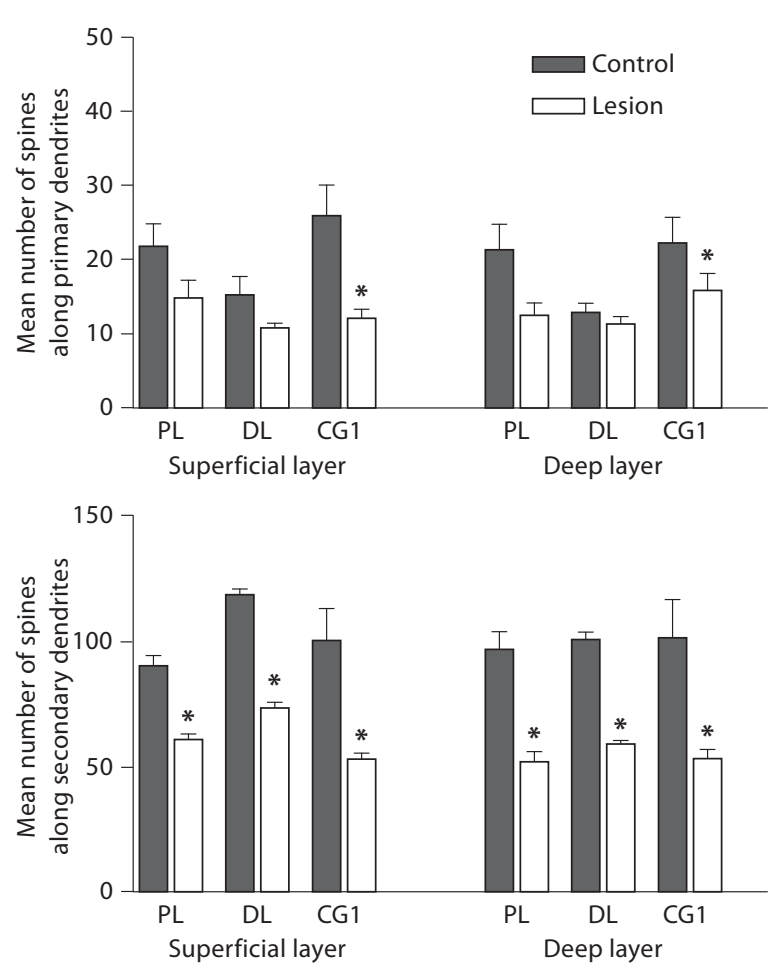

Fig. 9. Histograms showing the mean number of spines on primary and secondary dendrites in all 3 regions. The data show a decrease in spines on secondary basilar dendrites in all 3 regions lesions vs. controls. $\mathrm{PL}=$ Prelimbic; $\mathrm{DL}=$ dorsolateral; $\mathrm{CG} 1=$ cingulate cortex $1 .{ }^{*}$ Significant decrease.

the prelimbic region showed no significant decrease in spines at $20 \mu \mathrm{m}$ (control: $0.092 \pm 0.054$, lesion: $0.067 \pm$ $0.055, \mathrm{p}=0.15, \mathrm{t}=1.19)$. However, at $60 \mu \mathrm{m}$ there was a $33.66 \%$ decrease in spine density (control: $0.413 \pm 0.13$, lesion: $0.274 \pm 0.13, \mathrm{p}=0.001, \mathrm{t}=7.17)$. Cells analyzed at $20 \mu \mathrm{m}$ in superficial layers of the dorsolateral anterior cortex showed a significant $38 \%$ decrease in spine density (control: $0.128 \pm 0.076$, lesion: $0.079 \pm 0.056, \mathrm{p}=$ $0.012, \mathrm{t}=3.54)$. Cells at $60 \mu \mathrm{m}$ showed a significant $38 \%$ decrease in spine density (control: $0.451 \pm 0.18$, lesion: $0.28 \pm 0.19, \mathrm{p}=0.001, \mathrm{t}=7.17$ ). In the deep layers there was no significant difference in spine density at $20 \mu \mathrm{m}$ (control: $0.099 \pm 0.072$, lesion: $0.08 \pm 0.06, \mathrm{p}=0.17, \mathrm{t}=$ 1.08 ), while at $60 \mu \mathrm{m}$ there was a significant $22 \%$ decrease in spine density (control: $0.366 \pm 0.12$, lesion: $0.284 \pm$ $0.15, \mathrm{p}=0.03, \mathrm{t}=3.31$ ). Thalamic inputs to the PFC are found on apical and basilar dendrites and their spines on pyramidal cells in layers III and V, more specifically on 


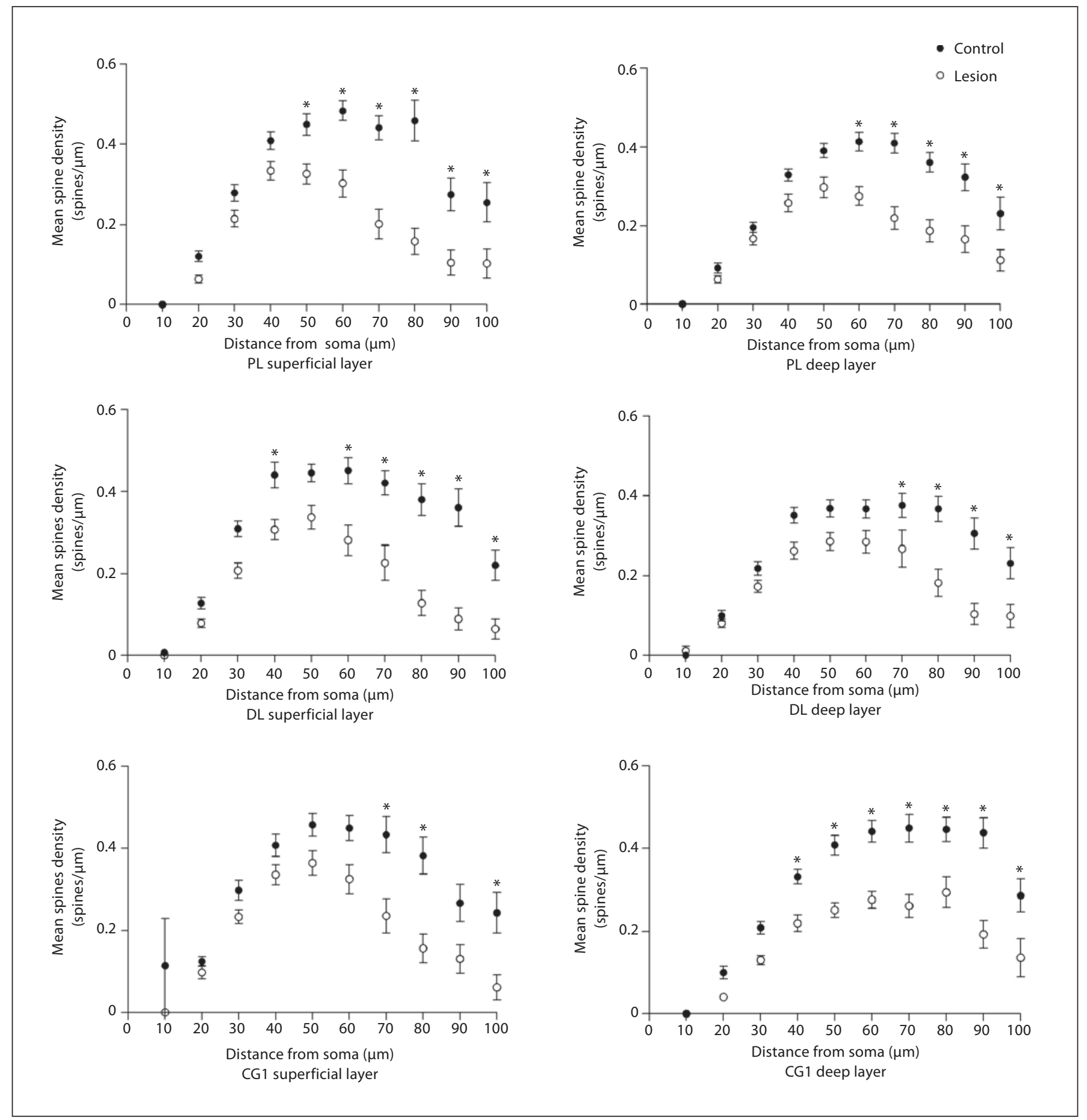

Fig. 10. Sholl analysis showing spine density vs. distance from the soma. The data show that spine loss was greatest in the distal segments of the dendrites compared to the proximal segments comparing lesion vs. controls. $\mathrm{PL}=$ Prelimbic; $\mathrm{DL}=$ dorsolateral. 
thinner basilar dendrites, suggesting that they would be found further from the soma as dendrites taper as they get further from the soma of pyramidal cells [35-37]. Our data suggest that the loss of spines is found within the zones of the MD afferent input to the cortical regions examined.

\section{Discussion}

Our results suggest that an early postnatal lesion of the MD leads to disruption of dendritic development of the pyramidal cells in the PFC regions connected to the MD. Following a lesion at $\mathrm{P} 4$, we found significant decreases in MAP2 immunostaining, number of dendrites and spine density in the $3 \mathrm{PFC}$ regions innervated by the MD. The observed decreases appear to be unrelated to a loss of cells in the PFC as seen by no change in cell density in any of the regions examined. The lesions observed were large enough to suggest loss of input as seen in the volume decrease and in the number of cells lost due to the lesion. The loss of immunostaining is not correlated with the size of the lesion, suggesting that a minimum number of afferents is required for the development of the pyramidal cells and that once lost the effect does not increase. Further studies will be needed to determine if this is so. Thalamic afferents synapse on pyramidal cells in layers III and V, which may account for the effect on both layers $[35-37,45]$. Our decision to perform the lesion at $\mathrm{P} 4$ was based on the study by Kolb and Cioe [46], showing that early cortical lesions cause morphological and behavioral changes but lesions after P7 cause no long-term effects in either morphology or behavior. Furthermore, Volk and Lewis [47] found no differences in GAD67 in the PFC following a lesion of the MD during puberty. Gizerian et al. [48] showed that an intraperitoneal injection of a neurosteroid at P5 caused a decrease in cell number in the MD in adults, but an injection at P2 did not. Additionally, Van Eden [1] showed that thalamocortical afferents arrive at the cortex before corticothalamic afferents arrive at the thalamus, suggesting that thalamocortical afferents may help specify a region. While $\mathrm{P} 4$ is the time when the adult pattern of lamination and connectivity is present in most rat cortical regions, this is not so for the PFC; these processes are still ongoing at P8 [1]. Myelination of long fiber tracts occurs late in the first postnatal week [1], and neurotrophin-3 expression, a marker for the primary targets of the thalamic innervation, appears in layer III at this time [49]. These data suggest that there is a critical window during development in which thalamic changes could influence PFC development and adult function; our choice of P4 falls within this window. Normal activity in afferents innervating the PFC appears to be required for normal PFC development and neuronal function. Van Eden [1] lesioned the MD on the day of birth, but the only observed change in the cortex was a decrease in cortical width in certain regions at P35 and a mild behavioral impairment in adulthood on a spatial delayed alternation task. They might have observed only subtle anatomical changes because of the relatively young age at which they sacrificed the animals. Data suggest that manipulations prior to $\mathrm{P} 7$ have permanent lasting results that persist in adulthood. Manipulations that occur after P7 do not cause similar problems, suggesting that the manipulations have little or no effect on the development of that cortical region [46].

Research has shown that dendritic maturation appears to be dependent upon synaptic activity [50]. Deafferentation causes many changes in the target regions, leading to loss of dendrites and reduction in neuropil [50]. Much of dendritic development occurs postnatally in rodents, and our lesion occurred at a time prior to myelination of the axons from the MD to the PFC and prior to the final development of the region. While the MD does have connections to the contralateral PFC, those connections are minimal, and we do not believe that they would have an affect on the opposing cortex. A limitation of the present study is a lack of sham-operated controls. Future studies will include this control group to determine if the operation has an affect on the developing cortex.

During central nervous system development, the thalamic afferents arrive at the developing cortex and enter the subplate prior to the birth of their primary target cell layer [30, 34, 35, 50-53]. For most cortical areas, layer IV is the primary target for thalamic afferents; however, in dysgranular cortices such as areas 9, 10 and 32 in humans and Cg1, prelimbic and dorsolateral anterior cortex in rats, there is a very small layer IV, and the thalamic afferents have a dense input in layers II-III and also layer V [35-37]. The excitatory projections from the thalamus to the cortex synapse primarily on layer III and layer V apical dendrites and thin basilar dendrites, suggesting distal segments of the basilar dendrites [35-37]. Thalamic afferents may aid in the development of the cortex and, more specifically, in the activity-dependent process of dendritic pruning $[8,54-57]$. In addition to thalamic afferents, GABAergic cells play a crucial role in pyramidal cell function. GABAergic cells can deinactivate dendritic voltage-sensitive channels, suggesting that they may prime dendrites for depolarizing input [58-62] as well as 
hyperpolarizing pyramidal cells, thus playing a role in controlling neuronal excitability. Neurons adapt their neuritic field to maintain a particular level of bioelectric activity $[8,54-57]$. Changes in the perceived activity of a cell, therefore, may be reflected in the number and length of dendritic branches. Once the level of bioelectric activity is set, changes in activity around the cell cannot alter neuritic morphology further [8]. Electrical stimulation or depolarization has been shown to increase neurite outgrowth. These effects are dependent on the influx of extracellular calcium [63-65]. The rate of growth cone extension is dependent upon an optimal level of intracellular calcium, and if calcium levels fall below this level growth cones will stop elongating or retract [63-65]. If the level of intracellular calcium is lowered, this will arrest axonal outgrowth and stop net addition of dendrites and dendritic branches, at least in part, by inhibiting the polymerization of actin. Our data suggest that loss of the MD input during the first postnatal week leads to loss of dendrites and spines whose development is activity dependent.

Much data suggests that schizophrenia, like autism and attention deficit disorder, has its origins rooted in development [18]. Loss of innervation of the MD to the PFC may account for the morphological changes observed in schizophrenia, and these changes may be due to alterations in calcium signaling. Calcium influx leads to release of neurogranin from calmodulin, which then binds to calcium, forming the calcium-calmodulin complex. This complex in turn activates CaMK II, which leads to a cascade of events with one of the outcomes being phosphorylation of MAP2. Phosphorylation of MAP2 leads to stabilization of microtubules and dendritic formation. Thus, lowered levels of intracellular calcium during development could lead to the changes in neuronal morphology that have been observed in schizophrenia. Data from our laboratory have shown a decrease in MAP2 [38] and in the number of basilar dendrites [66] and spines in schizophrenia. Additional data from our laboratory have shown a decrease in expression of neurogranin [67] and calmodulin [68], two regulators of internal calcium. Neurogranin binds calmodulin, therefore preventing the interaction of calcium with calmodulin. Calcium, when bound to calmodulin, activates calcium/ calmodulin II, which leads to phosphorylation of MAP2. Current research lends evidence to the theory that disorders like autism, schizophrenia and attention deficit disorder are due to an imbalance of excitation and inhibition through altered neural circuitry [18]. Evidence of altered genetics supports the above theory [18]. The thalamus is the primary excitatory input to the cortical regions involved in autism and schizophrenia, and loss of this input may lead to the excitation/inhibition imbalance. It is important, therefore, to better understand the role the $\mathrm{MD}$ plays in the development of the PFC to begin to understand the etiology of neuropsychiatric disorders like schizophrenia and autism. The loss of excitatory input from the MD to the pyramidal cells in the PFC leads to altered dendritic development. Our data suggest that a volume loss of $9 \%$ in the MD and a cell loss of $15 \%$ leads to a decrease in MAP2 expression, number of basilar dendrites and spine density in the PFC in rats similar to the loss observed in schizophrenics, suggesting that alterations in morphology and calcium signaling may be due to a loss of afferents from the MD. Future studies are needed to determine the impact of the loss of input from the MD to the PFC on the function of the pyramidal cells and their interactions with cells in local and long-distant circuits.

\section{Acknowledgments}

We would like to thank Meghan Galligan for her time and effort on the project. The work was supported by a grant from the Shuster Foundation and by NIH RCMI G12RR-03060.
References
4 Faull RL, Mehler WR: Thalamus; in Paxinos G (ed): The Rat Nervous System. Forebrain and Midbrain. New York, Academic Press, 1985, vol 1, pp 129-161. amus and the prefrontal cortex in the rat. J Comp Neurol 1986;244:349-359.

- 2 Molnar Z: Development and evolution of thalamocortical interactions. Eur J Morphol 2000;38:313-320.

3 Byne W, Buchsbaum MS, Kemether E, Purohit P, Haroutunian V, Jones L: Postmortem assessment of thalamic nuclear volumes in schizophrenia. Am J Psychiatry 2001;159: $59-65$.
5 Negyessy L, Goldman-Rakic PS: Morphometric characterization of synapses in the primate prefrontal cortex formed by afferents from the mediodorsal thalamic nucleus. Exp Brain Res 2005;64:148-154.

$\checkmark 6$ Benes FM: Myelination of cortical-hippocampal relays during late adolescence. Schizophr Bull 1989;15:585-593. 
7 Rajan I, Cline HT: Glutamate receptor activity is required for normal development of tectal cell dendrites in vivo. J Neurosci 1998; 18:7836-7846.

$>8$ Van Ooyen A, van Pelt J, Corner MA: Implication of activity-dependent neurite outgrowth for neuronal morphology and network development. J Theor Biol 1995;172: 63-82.

$\checkmark 9$ Chakravarthy B, Morley P, Whitfield J: $\mathrm{Ca}^{2+}$ calmodulin and protein kinase Cs: a hypothetical synthesis of their conflicting convergences on shared substrate domains. Trends Neurosci 1999;22:12-16.

-10 Wayman GA, Impey S, Marks D, Saneyoshi T, Grant WF, Derkach V, Soderling TR: Activity-dependent dendritic arborization mediated by CaM-kinase I activation and enhanced CREB-dependent transcription of Wnt-2. Neuron 2006;50:897-909.

11 Gerendasy D: Homeostatic tuning of $\mathrm{Ca}^{2+}$ signal transduction by members of the calpacitin protein family. J Neurochem Res 1999;58:107-119.

-12 Zou D-J, Cline HT: Postsynaptic calcium/ calmodulin-dependent protein kinase II is required to limit elaboration of presynaptic and postsynaptic neuronal arbors. J Neurosci 1999;19:8909-8918.

13 Borodinsky LN, Coso OA, Fiszman ML: Contribution of $\mathrm{Ca}^{2+}$ calmodulin-dependent kinase II and mitogen-activated protein kinase to neural activity-induced neurite outgrowth and survival of cerebellar granule cells. J. Neurochem 2002;80:1062-1070.

14 Mainen ZF, Sejnowski TJ: Influence of dendritic structure on firing pattern in model neocortical neurons. Nature 1996;382:363366.

$>15$ Hely TA, Graham B, van Ooyen A: A computational model of dendritic elongation and branching based on MAP2 phosphorylation. J Theor Biol 2001;210:375-384.

-16 Diez-Guerra FJ, Avila J: An increase in phosphorylation of microtubule-associated protein 2 accompanies dendrite extension during the differentiation of cultured hippocampal neurons. Eur J Biochem 1994;227: 68-77.

17 Audesirk G, Cabell L, Kern M: Modulation of neurite branching by protein phosphorylation in cultured rat hippocampal neurons. Dev Brain Res 1997;102:247-260.

18 Stoeckli ET: What does the developing brain tell us about neural disease? Eur J Neurosci 2012;35:1811-1817.

19 Harrison LM, Mair RG: A comparison of the effects of frontal cortical and thalamic lesions on measures of spatial learning and memory in the rat. Behav Brain Res 1996;75: 195-206.

20 Stokes KA, Best PJ: Mediodorsal thalamic lesions impair 'reference' and 'working' memory in rats. Physiol Behav 1990;47:471-476.
21 Isseroff A, Rosvold HE, Galkin TW, Goldman-Rakic PS: Spatial memory impairments following damage to the mediodorsal nucleus of the thalamus in rhesus monkeys. Brain Res 1982;232:97-113.

22 Aggleton JP, Mishkin M: Visual recognition impairment following medial thalamic lesions in monkeys. Neuropsychologia 1983; 21:189-197.

23 Garter JA, de Bruin JP: Chronic neonatal MK-801 treatment results in an impairment of spatial learning in the adult rat. Brain Res 1992;580:12-17.

24 Sircar R, Rudy JW: Repeated neonatal phencyclidine treatment impairs performance of a spatial table in juvenile rats. Ann NY Acad Sci 1998;844:303-309.

25 Sircar R: Postnatal phencyclidine-induced deficit in adult water maze performance is associated with N-methyl-D-aspartate receptor upregulation. Int J Dev Neurosci 2003;21:159-167.

26 Stefani MR, Moghaddam B: Transient Nmethyl-D-aspartate receptor blockade in early development causes lasting cognitive deficits relevant to schizophrenia. Biol Psychiatry 2005;57:433-436.

27 Wang C, McInnis J, Ross-Sanchez M, Shinnick-Gallagheere P, Wiley JL, Johnson KM: Long-term behavioral and neurodegenerative effects of perinatal phencyclidine administration: implications for schizophrenia. Neuroscience 2001;107:535-550.

28 Pehrson AL, Walenting DM, Wood JT, Vunck SA, Porter JH: Early postnatal antagonism of glutamatergic NMDA receptors impairs reference and working memory performances, but has no effect on locomotor activity in male C57Bl/6 mice. 2007;18:S1S11.

29 Bubenikova-Valesova V, Horacek J, Vrajova M, Hoschl C: Models of schizophrenia in humans and animals based on inhibition of NMDA receptors. Neurosci Behav Rev 2008; 32:1014-1023.

30 Gabbott PL, Warner TA, Jays PR, Bacon SJ: Areal and synaptic interconnectivity of prelimbic (area 32), infralimbic (area 25) and insular cortices in the rat. Brain Res 2003;993: 59-71.

31 Paxinos G, Kus L, Ashwell KW, Watson C: Chemoarchitectonic Atlas of the Rat Forebrain. London, Academic Press, 1999.

32 Paxinos G, Watson C: The Rat Brain in Stereotaxic Coordinates. Sydney, Academic Press, 1986.

33 Pirot S, Jay TM, Glowinski J, Thierry AM: Anatomical and electrophysiological evidence for an excitatory amino acid pathway from the thalamic mediodorsal nucleus to the prefrontal cortex. J Neurosci 1994;6: 1225-1234.

34 Negyessy L, Hámori J, Bentivoglio M: Contralateral cortical projection to the mediodorsal thalamic nucleus: origin and synaptic organization in the rat. Neuroscience 1998; $84: 741-753$
35 Kuroda M, Murakami K, Kishi K, Price JL: Thalamic synapses between axons from the mediodorsal thalamic nucleus and pyramidal cells in the prelimbic cortex of the rat. J Comp Neurol 1995;356:143-151.

36 Kuroda M, Murakami K, Shinkai M, Ojima $\mathrm{H}$, Kishi K: Electron microscopic evidence that axon terminals from the mediodorsal thalamic nucleus make direct synaptic contacts with callosal cells in the prelimbic cortex of the rat. Brain Res 1995;677:348-353.

37 Kuroda M, Yokofujita J, Murakami K: An ultrastructural study of the neural circuit between the prefrontal cortex and the mediodorsal nucleus of the thalamus. Prog Neurobiol 1998;54:417-458.

-38 Jones L, Johnson N, Byne W: Alterations in MAP2 staining in area 9 and 32 of schizophrenic prefrontal cortex. Psychiatry Res 2002;114:137-148.

39 Pakkenberg B: Pronounced reduction of total neuron number in mediodorsal thalamic nucleus and nucleus accumbens in schizophrenics. Arch Gen Psychiatry 1990;47: 1023-1028.

40 Pakkenberg B: The volume of the medial dorsal thalamic nucleus in treated and untreated schizophrenics. Schizophr Res 1992; 7:95-100.

41 Popken GJ, Bunney WE Jr, Potkin SG, Jones EG: Subnucleus-specific loss of neurons in medial thalamus of schizophrenics. Proc Natl Acad Sci USA 2000;97:9276-9280.

42 Young KA, Manaye KF, Liang C-L, Hicks PB, German DC: Reduced numbers of mediodorsal and anterior thalamic neurons in schizophrenia. Biol Psychiatry 2000;47:944953.

43 Byne W, Buchsbaum MS, Kemether E, Hazlett EA, Shinwari A, Mitropoulou V, Siever LJ: Magnetic resonance imaging of the thalamic mediodorsal nucleus and pulvinar in schizophrenia and schizotypal personality disorder. Arch Gen Psychiatry 2001;58: 133-140.

44 Staal WG, Hulshoff Pol HE, Schnack HG, Hoogendoorn ML, Jellema K, Kahn RS: Structural brain abnormalities in patients with schizophrenia and their healthy siblings. Am J Psychiatry 2000;157:416-421.

45 Berendse HW, Groenewegen HJ: Restricted cortical termination fields of the midline and intralaminar thalamic nuclei in the rat. Neuroscience 1991;42:73-102.

$\checkmark 46$ Kolb B, Cioe J: Recovery from early cortical damage in rats. VIII. Earlier may be worse: behavioral dysfunction and abnormal cerebral morphogenesis following perinatal frontal cortical lesions in the rat. Neuropharmacology 2000;39:756-764.

47 Volk DW, Lewis DA: Effects of a mediodorsal thalamus lesion on prefrontal inhibitory circuitry: implications for schizophrenia. Biol Psychiatry 2003;53:385-389. 
-48 Gizerian SS, Marrow AL, Lieberman JA, Grobin AC: Neonatal neurosteroid administration alters parvalbumin expression and neuron number in medial dorsal thalamus of adult rats. Brain Res 2004;1012:66-74.

49 Ma L, Harada T, Harada C, Romero M, Herbet JM, McConnell SK, Parada LF: Neurotrophin-3 is required for appropriate establishment of thalamocortical connections. Neuron 2002;36:623-634.

50 Berry M: Development of the cerebral neocortex of the rat; in Gottlieb G (ed): Aspects of Neurogenesis. New York, Academic Press, 1974, vol 2, pp 7-67.

51 Sinopoli KJ, Floresco SB, Galea LA: Systemic and local administration of estradiol into the prefrontal cortex or hippocampus differentially alters working memory. Neurobiol Learn Mem 2006;86:293-304.

52 Gisquet-Verrier P, Delatour B: The role of the rat prelimbic/infralimbic cortex in working memory: not involved in the short-term maintenance but in the monitoring and processing functions. Neuroscience 2006;141: 585-596.

53 Flores G, Alquicer G, Silva-Gomez AB, Zaldivar G, Stewart J, Quirion R, Srivastava LK: Alterations in dendritic morphology of prefrontal cortical and nucleus accumbens neurons in post-pubertal rats after neonatal excitotoxic lesions of the ventral hippocampus. Neuroscience 2005;133:463-470.
4 Van Pelt J, van Ooyen A, Corner MA: Growth cone dynamics and activity-dependent processes in neuronal network development. Prog Brain Res 1996;108:333-346.

55 Kossel AH, Williams CV, Schweizer M, Kater SB: Afferent innervation influences the development of dendritic branch and spines via both activity-dependent and non-activity-dependent mechanisms. J Neurosci 1997; 17:6314-6324.

56 Baker RE, van Pelt J: Cocultured, but not isolated, cortical explants display normal dendritic development: a long-term quantitative study. Dev Brain Res 1997;98:21-29.

57 Wise SP, Fleshman JW, Jones EG: Maturation of pyramidal cell form in relation to developing afferent and efferent connections of the rat somatic sensory cortex. J Neurosci 1979;4:1275-1297.

58 Callaway JC, Lasser-Ross N, Ross WN: IPSPs strongly inhibit climbing fiber-activated $\left[\mathrm{Ca}^{2+}\right] \mathrm{i}$ increases in the dendrites of cerebellar Purkinje neurons. J Neurosci 1995;15: 2777-2787.

59 Magee JC, Johnston D: Synaptic activation of voltage-gated channels in the dendrites of hippocampal pyramidal neurons. Science 1995;268:301-304.

60 Magee JC, Johnston D: Characterization of single voltage-gated $\mathrm{Na}^{+}$and $\mathrm{Ca}^{2+}$ channels in apical dendrites of rat CA1 pyramidal neurons. J Physiol 1995;487:67-90.

-61 de la Pena E, Geijo-Barrientos E: Laminar localization, morphology, and physiology properties of pyramidal neurons that have the low-threshold calcium current in guinea pig medial frontal cortex. J Neurosci 1996; 16:5301-5311.
62 Gillessen T, Alzheimer C: Amplification of EPSPs by low $\mathrm{Ni}^{2+}$ and amiloride-sensitive $\mathrm{Ca}^{2+}$ channels in apical dendrites of rat CA1 pyramidal neurons. J Neurosci 1997;77: 1639-1643.

63 Ramakers GJ, Avci B, van Hulten P, van Ooyen A, van Pelt J, Pool CW, Lequin MB: The role of calcium signaling in early axonal and dendritic morphogenesis of rat cerebral cortex neurons under non-stimulated growth conditions. Dev Brain Res 2001;126: 163-172.

-64 Petit TL, LeBoutillier JC, Gregorio A, Libstug $\mathrm{H}$ : The pattern of dendritic development in the cerebral cortex of the rat. Dev Brain Res 1988;41:209-219.

65 Kater SB, Mattson MP, Cohan C, Connor J: Calcium regulation of the neuronal growth cone. Trends Neurosci 1988;11:315-321.

66 Broadbelt K, Byne WB, Jones LB: Evidence for a decrease in primary and secondary basilar dendrites on pyramidal cells in area 32 of schizophrenic prefrontal cortex. Schizophr Res 2002;58:75-81.

67 Broadbelt K, Ramprasaud A, Jones LB: Evidence of altered neurogranin immunoreactivity in areas 9 and 32 of schizophrenic prefrontal cortex. Schizophr Res 2006;87:6-14.

68 Broadbelt K, Jones LB: Evidence of altered calmodulin immunoreactivity in areas 9 and 32 of prefrontal schizophrenic prefrontal cortex. J Psychiatr Res 2008;42:612-621. 